Article

\title{
Electrochemical Reduction of Coumarins at a Film-Modified Electrode and Determination of Their Levels in Essential Oils and Traditional Chinese Herbal Medicines
}

\section{Lai-Hao Wang * and Hsiu-Hua Liu \\ Department of Applied Chemistry, Chia Nan University of Pharmacy and Science, 60 Erh-Jen Road, Section 1, Jen Te, Tainan 71743, Taiwan; E-mail: appys31@yahoo.com.tw (H-H. L.)}

* Author to whom correspondence should be addressed; E-mail: e201466wang@msa.hinet.net; Fax: +886-6-266-7319.

Received: 22 June 2009; in revised form: 26 August 2009 / Accepted: 9 September 2009 / Published: 11 September 2009

\begin{abstract}
The electrochemical reduction of coumarins on glassy carbon and electrodeposited metal electrodes was investigated in a Britton-Robinson buffer $(\mathrm{pH}$ 1.87-11.98). The effects of various factors, such as the deposition material, time, and concentration of mercury, on the precision of the analysis were explored. The possible reaction mechanism of the reduction process with regards to scan rates, peak potentials, and currents is discussed. Electroreduction was used to quantitatively determine the levels of coumarins in some essential oils and traditional Chinese herbal medicines. A comparison with high performance liquid chromatography analysis results shows good agreement.
\end{abstract}

Keywords: coumarins; essential oils and medicinal products; mercury-film electrode

\section{Introduction}

Coumarins, with a 2H-1-benzopyran-2-one nucleus, and furocoumarins (psoralens, 7H-furo[3,2-g[1]benzopyran-7-one]) are biologically active compounds with effective anti-convulsant, anti-tumoral, anti-inflammatory, and anti-viral properties [1-7]. Additionally, coumarins have been 
widely used as flavoring compounds because of their sweet and aromatic odor [8]. Coumarin dyes are organic materials with high solar-to-energy transfer-efficiency in dye-sensitized solar cells (DSC) [9]. Therefore, overall coumarins are considered important natural compounds.

Various spectrophotometric [10-13], liquid chromatography-mass spectrometric (LC-MS) [14-24], and gas chromatography-mass spectrometric (GC-MS) [25-27] methods have been used to determine coumarin levels in plants and foods. However, most of these methods involve only the extraction and identification of chemical constituents in natural plants. There are a few reports in the literature [28-29] on the determination of urinary metabolites after ingesting medicinal plants, but there are only a few published reports [30-33] on the behavior of coumarin derivatives. Furthermore, there is only one published report [34] concerning the use of using electrochemical oxidation to determine coumarin levels in plants.

In this work, we electrochemically reduced coumarins using a bare glassy carbon electrode (GCE) and mercury (II)-nitrate-[ $\left.\mathrm{Hg}\left(\mathrm{NO}_{3}\right)_{2}\right]$ and lead-acetate-[ $\left.\mathrm{Pb}\left(\mathrm{CH}_{3} \mathrm{COO}\right)_{2}\right]$ modified-GCEs, respectively. We investigated coumarin levels using direct current as well as cyclic and differential pulse voltammetry (DPV). The optimum experimental conditions for determining coumarin levels in some essential oils and traditional Chinese herbal medicines are also described in this paper.

\section{Results and Discussion}

\subsection{Choice of analytical method}

The polarographic behavior of coumarins indicates that at a $\mathrm{pH}>11.2$, they exist entirely in the lactone form (I), and at a $\mathrm{pH}<6.8$ entirely as coumaric acid (II) (Scheme 1); both forms are present when the $\mathrm{pH}$ is between 6.8 and 11.2 [35].

Scheme 1. Coumarin: Both forms depend on $\mathrm{pH}$.

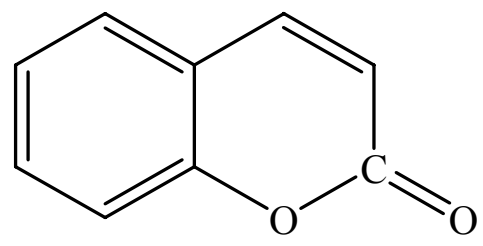

lactone form (I)
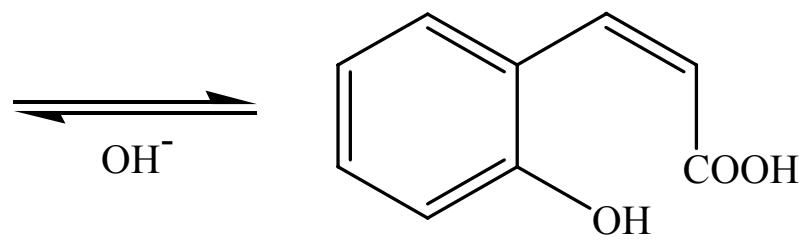

coumaric acid (II)

The reduction of coumarin in lithium perchlorate was studied on a GCE, thin-film mercury deposited on a GCE (Hg/GCE), and thin-film lead deposited on a GCE (Pb/GCE). Peak potentials were $-1.370 \mathrm{~V}(\mathrm{GCE}),-1.360 \mathrm{~V}(\mathrm{~Pb} / \mathrm{GCE})$, and $-1.356 \mathrm{~V}(\mathrm{Hg} / \mathrm{GCE})$; peak currents were $11.818 \mu \mathrm{A}$ (GCE), $15.457 \mu \mathrm{A}(\mathrm{Pb} / \mathrm{GCE})$, and $20.537 \mu \mathrm{A}(\mathrm{Hg} / \mathrm{GCE})$, which indicated that $\mathrm{Hg} / \mathrm{GCE}$ performed best. Because the thin-film mercury was more sensitive than the dropping mercury electrode [36], the $\mathrm{Hg} / \mathrm{GCE}$ was used to determine the levels of coumarins in the essential oils and traditional Chinese herbal medicines. 
Figure 1. Differential pulse voltammograms of coumarin $\left(6.22 \times 10^{-4} \mathrm{M}\right)$ in lithium perchlorate: solid line (-) at GCE; dotted line (...) at lead-modified GCE (Pb/GCE); dashed line (---) at mercury-modified GCE (Hg/GCE); scan rate: $10 \mathrm{mV}$; pulse height: $10 \mathrm{mV}$.

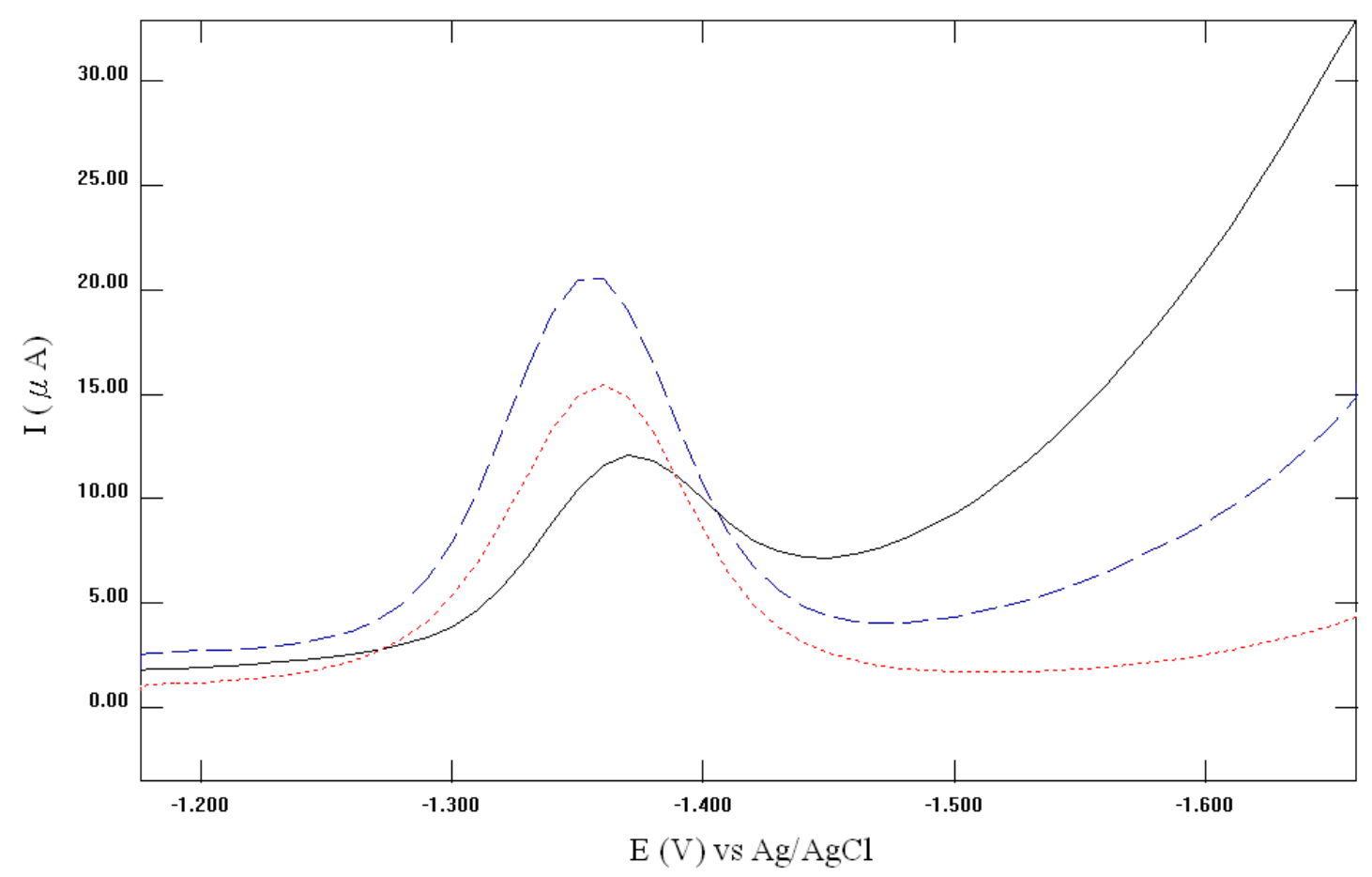

The deposition conditions primarily affect the specific surface area of the metal catalyst. We investigated the optimum conditions for electrochemically depositing metal onto the GCE. We investigated the effect of the thickness of the metal layer by coating the GCE with deposition solution at 2, 4, 6, and $8 \mathrm{~min}$, respectively. Mercury film was electrochemically deposited for 4 min onto a GCE in a $0.1-\mathrm{M}$ acetate buffer aqueous solution of $2.06 \times 10^{-3} \mathrm{M}$ of $\mathrm{Hg}\left(\mathrm{NO}_{3}\right)_{2}$ at a potential between 0.0 and $+1.2 \mathrm{~V}$ (vs. $\mathrm{Ag} / \mathrm{AgCl}$ ) at $10 \mathrm{mV} / \mathrm{s}$. These values were used because the slope and the linear concentration range of the calibration graph were the largest using them than using other values.

The effect of $\mathrm{pH}$ on the $\mathrm{E}_{1 / 2}$ (half-wave potential) value of coumarin was studied over the $\mathrm{pH}$ range of 2-12. The average values of $\mathrm{dE}_{1 / 2} / \mathrm{dpH}$ of coumarin in acidic and basic solutions were 0.057 and $0.0018 \mathrm{~V} / \mathrm{pH}$, respectively. The result conformed to the relationship shown in the following equation:

$$
\mathrm{E}_{1 / 2}=\text { constant }+\mathrm{RT} / \alpha \mathrm{n}_{\mathrm{a}} \mathrm{F} \ln \left[\mathrm{H}^{+}\right] / \mathrm{K}+\left[\mathrm{H}^{+}\right]
$$

and indicated that, at a low $\mathrm{pH}$, the half-wave potentials rose as the $\mathrm{pH}$ increased. However, the half-wave potentials became constant at a $\mathrm{pH}>8$. The $\mathrm{E}_{1 / 2}$ values and $\mathrm{pH}$ values were keyed into the computer, and then the acid dissociation constant $\left(\mathrm{p} K_{\mathrm{a}}\right)$ value was determined using simple regression. The intersection (breakpoint) of the two linear parts occurred when the $\mathrm{p} K_{\mathrm{a}}=5.87$ (Figure 2). 
Figure 2. Plots of $-\mathrm{E}_{1 / 2}$ vs. $\mathrm{pH}$ for coumarin. Concentration: $6.22 \times 10^{-4} \mathrm{M}$.

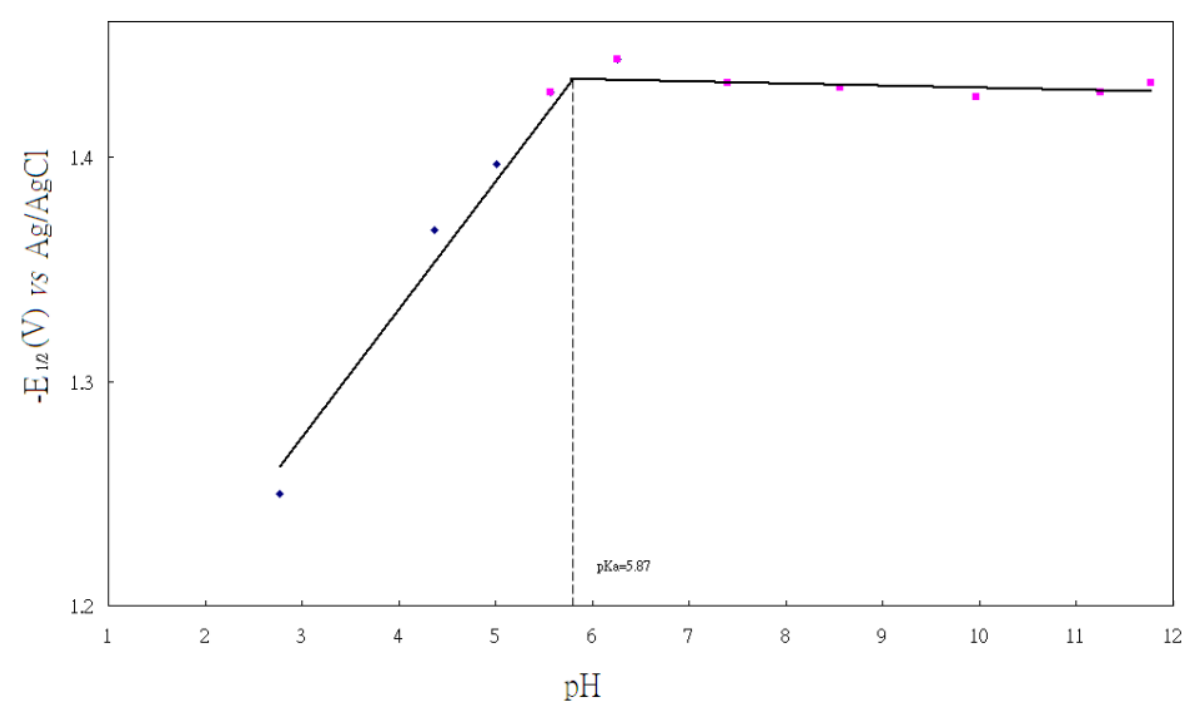

We then did comparative tests of supporting electrolytes - Britton-Robinson (BR) buffer (pH 1.87-12.05) and aqueous solutions containing phosphate buffer ( $\mathrm{pH}$ 6.52), acetate buffer ( $\mathrm{pH} 4.04)$, and $0.1 \mathrm{M}$ lithium perchlorate $(\mathrm{pH}$ 6.02). Differential pulse voltammograms of coumarin in BR buffered solution in the $\mathrm{pH}$ range of 5.01-10.01 at the $\mathrm{Hg} / \mathrm{GCE}$ showed two well-defined reductions at $-0.733 \mathrm{~V}$ and $-1.423 \mathrm{~V}$ (Table 1$)$.

Table 1. The effect of $\mathrm{pH}$ and supporting electrolytes on the differential pulse voltammetric peak potential and peak current of coumarin at mercury-modified glassy carbon electrode (Hg/GCE).

\begin{tabular}{|c|c|c|c|}
\hline Medium & pH & $E_{p}(V)$ & $\mathbf{i}_{\mathrm{p}}(\mu \mathrm{A})$ \\
\hline \multirow[t]{2}{*}{ BR buffer } & 5.01 & -0.733 & 1.086 \\
\hline & & -1.423 & 9.206 \\
\hline \multirow[t]{2}{*}{ BR buffer } & 6.82 & -0.785 & 2.819 \\
\hline & & -1.470 & 13.673 \\
\hline \multirow[t]{2}{*}{ BR buffer } & 7.46 & -0.768 & 4.730 \\
\hline & & -1.463 & 17.239 \\
\hline \multirow[t]{2}{*}{ BR buffer } & 8.56 & -0.736 & 2.258 \\
\hline & & -1.429 & 18.217 \\
\hline \multirow[t]{2}{*}{ BR buffer } & 9.46 & -0.713 & 2.673 \\
\hline & & -1.399 & 17.796 \\
\hline \multirow[t]{2}{*}{ BR buffer } & 9.96 & -0.756 & 2.548 \\
\hline & & -1.421 & 14.539 \\
\hline \multirow[t]{2}{*}{ BR buffer } & 10.01 & -0.797 & 2.321 \\
\hline & & -1.412 & 15.353 \\
\hline \multirow[t]{2}{*}{ Phosphate } & 6.52 & $--^{a}$ & $--^{a}$ \\
\hline & & -1.428 & 20.889 \\
\hline \multirow[t]{2}{*}{ Acetate buffer } & 4.04 & $--^{a}$ & $--^{-a}$ \\
\hline & & -1.348 & 11.664 \\
\hline \multirow[t]{2}{*}{$\mathrm{LiClO}_{4}$} & 6.02 & $--^{\mathrm{a}}$ & $--^{\mathrm{a}}$ \\
\hline & & -1.413 & 13.513 \\
\hline
\end{tabular}

BR, Britton-Robinson; ${ }^{a}$ Not determined. 
It seems reasonable that there is a 1-electron reduction to a dimer [37]. This $\mathrm{pH}$ agrees with that (9.96-10.96) at which the peak height markedly decreases. Hence, we concluded (i) that the lactone (I), which is, based on chemical evidence, the stable form in acid media, is reducible over the range of potentials studied; (ii) that the acid (II) is not reducible over that range; and (iii) that (I) is present to a negligible extent above $\mathrm{pH} 11.77$ and (II) to a negligible extent below pH 4.86. Above pH 10, the current decreases, because the lactone ring is opened to a non-reducible anion. Below $\mathrm{pH} 4$, there was no peak because of the overlying hydrogen discharge. The plot of Ip vs. pH (Figure 3) and the maximum peak current were obtained at $\mathrm{pH}<9$. For analytical purposes, the best supporting electrolytes for determining coumarins are BR buffers $(\mathrm{pH}$ 8.07-8.96) because they are more sensitive than others.

Figure 3. The effect of $\mathrm{pH}$ on the response current of $6.22 \times 10^{-4} \mathrm{M}$ coumarin in Britton-Robinson (BR) buffer at a thin-film mercury modified GCE (Hg/GCE); differential pulse voltammetry (DPV) scan rate: $10 \mathrm{mV} / \mathrm{s}$.

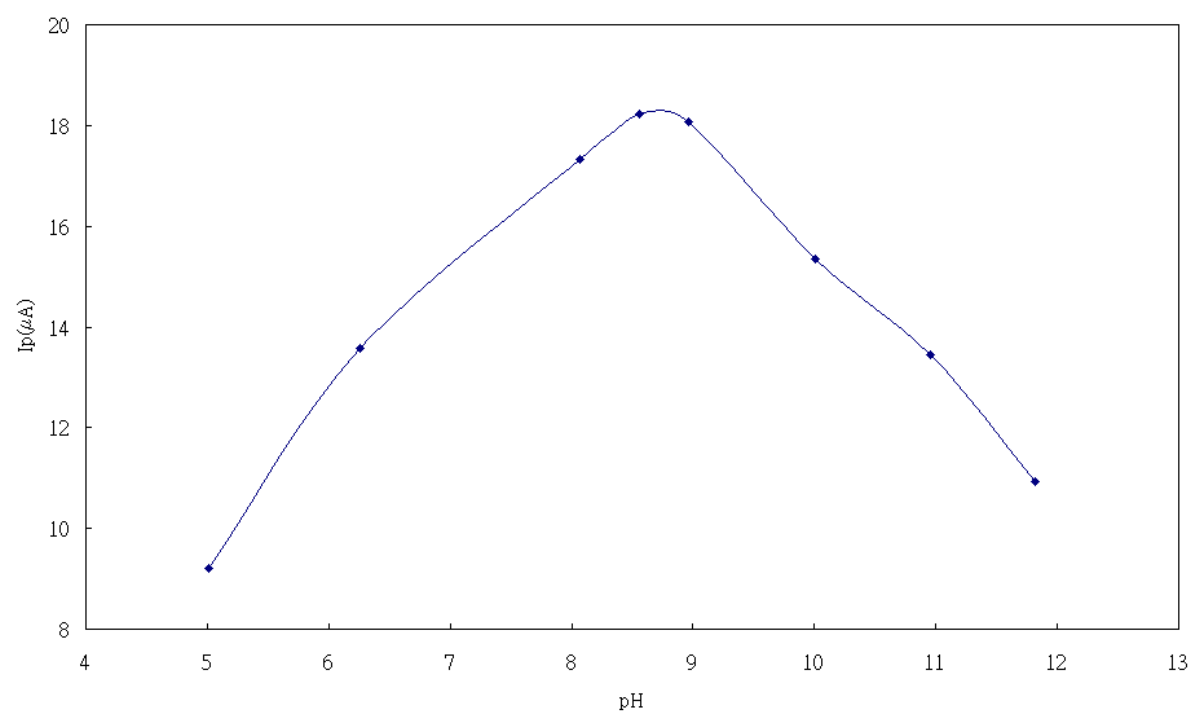

\subsection{The Hg/GCE catalyzed the reduction of coumarin}

Cyclic voltammograms were recorded at different concentrations as shown in Figure 4 . The $\mathrm{I}_{\mathrm{p}}$ is proportional to concentration, the regression equation was:

$$
\mathrm{y}=14.3+11.8 \times(\text { correlation coefficient: } \mathrm{r}=0.9981)
$$

The linearity between the peak current $\left(\mathrm{I}_{\mathrm{p}}\right)$ and the square root of the scan rate $v^{1 / 2}$ (Figure $5 \mathrm{~A}$ ) good, and it was characteristic of a diffusion-controlled process. The relationship between peak potential and the logarithm of the scan rate (Figure 5B) can be used to roughly estimate the number of electrons involved in the catalytic reduction. For a totally irreversible electrochemical reduction, the peak current in cyclic voltammograms can be expressed as:

$$
\mathrm{I}_{\mathrm{p}}=\left(2.99 \times 10^{5}\right) \mathrm{n}\left(\alpha \mathrm{n}_{\mathrm{a}}\right)^{1 / 2} \mathrm{AC}_{0} \mathrm{D}_{0}^{1 / 2} v^{1 / 2}
$$


where $I_{p}$ is the peak current, $n$ is the number of electrons involved in the reduction, $\alpha n_{a}$ is a parameter reflecting the irreversibility of the reduction, $A$ is the area of the electrode $\left(\mathrm{cm}^{2}\right), \mathrm{C}_{0}$ is the concentration of substrate, $v$ is the potential scan rate, and $\mathrm{D}_{0}$ is the diffusion coefficient of the substrate. The value of $n\left(\alpha n_{a}\right)$ can be calculated from the slope of the line in Figure 5A. On the other hand, the peak potential in cyclic voltammograms can be expressed as a function of the logarithm of the scan rate:

$$
\mathrm{E}_{\mathrm{p}}=\mathrm{k}+\left(0.03 / \alpha \mathrm{n}_{\mathrm{a}}\right) \log v .
$$

Therefore the number of electrons (n) involved in the reduction process can be obtained from data shown in Figures $5 \mathrm{~A}$ and B; a value of $\mathrm{n}=0.94$ electrons was obtained.

Figure 4. Cyclic voltammograms of coumarin in Britton-Robinson (BR) buffer (pH 5.83) at a thin-film mercury-modified GCE (Hg/GCE). Concentrations: (a) $2.723 \times 10^{-4} \mathrm{M}$; (b) $5.446 \times 10^{-4} \mathrm{M}$; (c) $1.089 \times 10^{-4} \mathrm{M}$; (d) $2.178 \times 10^{-4} \mathrm{M}$; scan rate: $12.5 \mathrm{mV} / \mathrm{s}$.

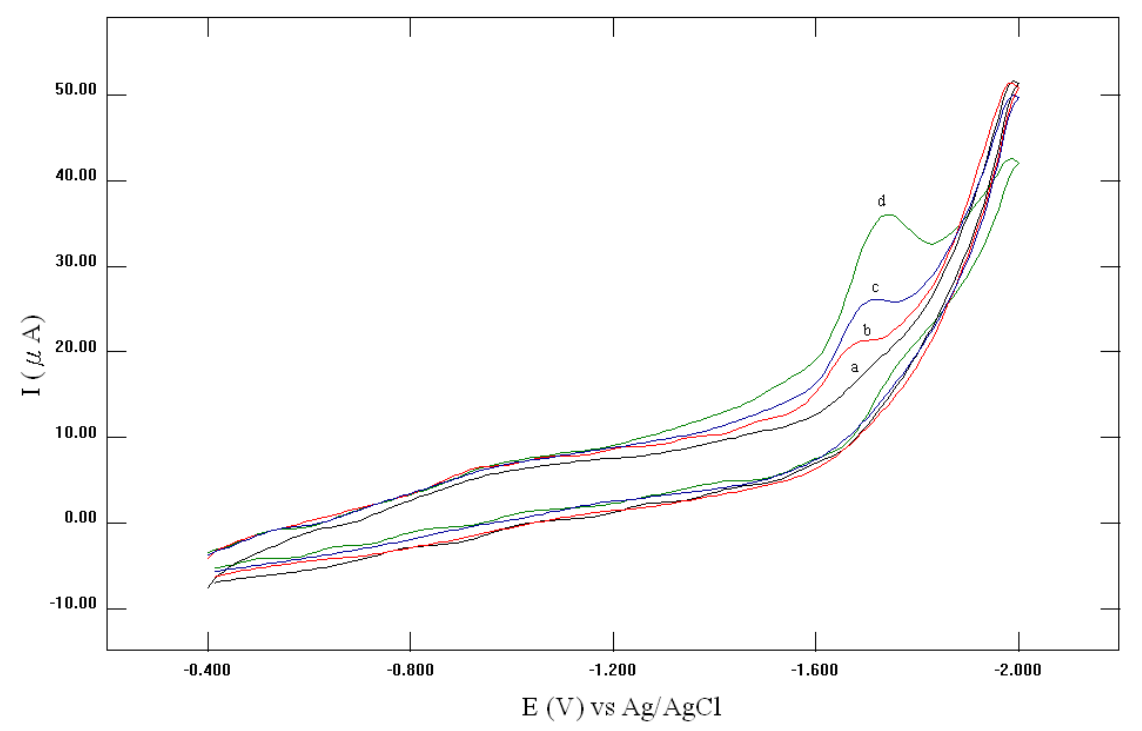

Figure 5. (A) Magnitude of peak current (Ip) as a function of the square of the scan rate for coumarin reduction. Concentration: $3.73 \times 10^{-3} \mathrm{M}$. (B) Real potentials of coumarin reduction as a function of the logarithm of the scan rate. Concentration: $3.73 \times 10^{-3} \mathrm{M}$.

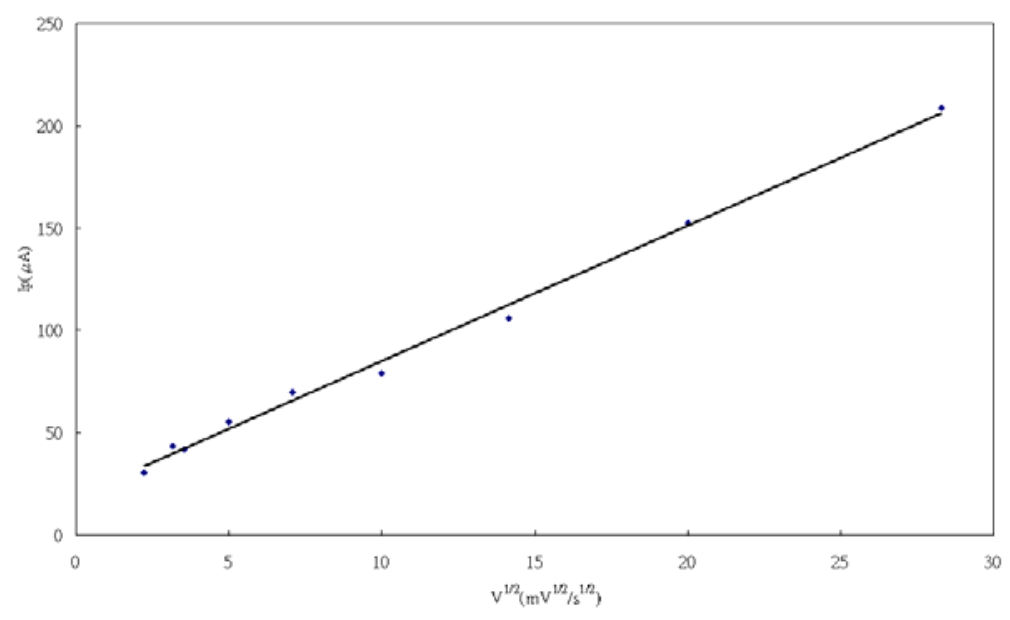


Figure 5. Cont.

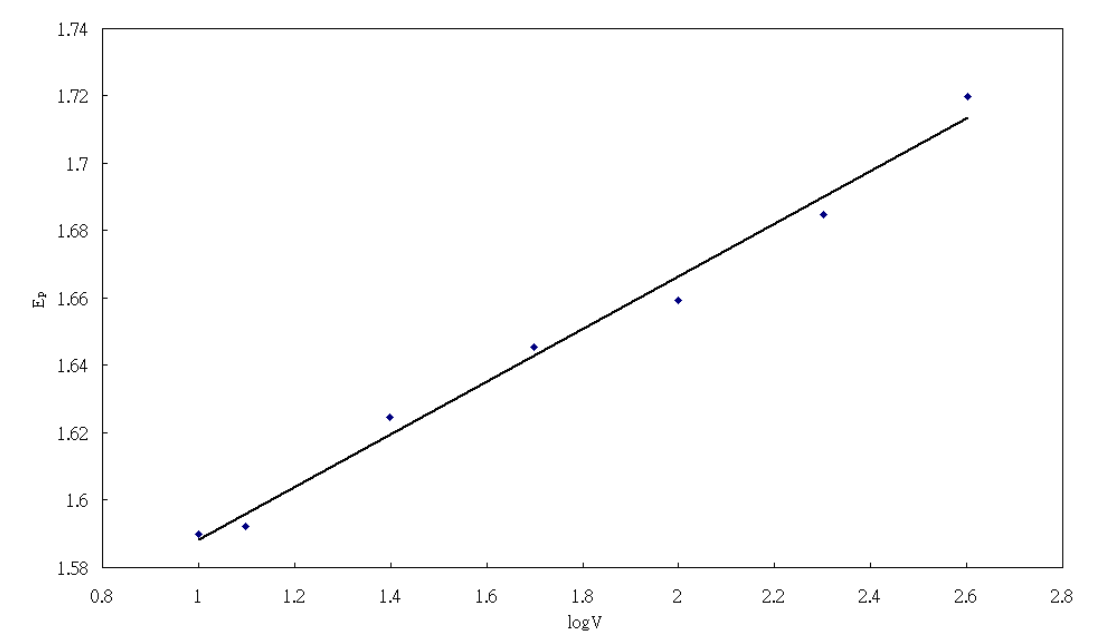

Therefore, a possible mechanism is given below in Scheme 2:

Scheme 2. Possible mechanism.

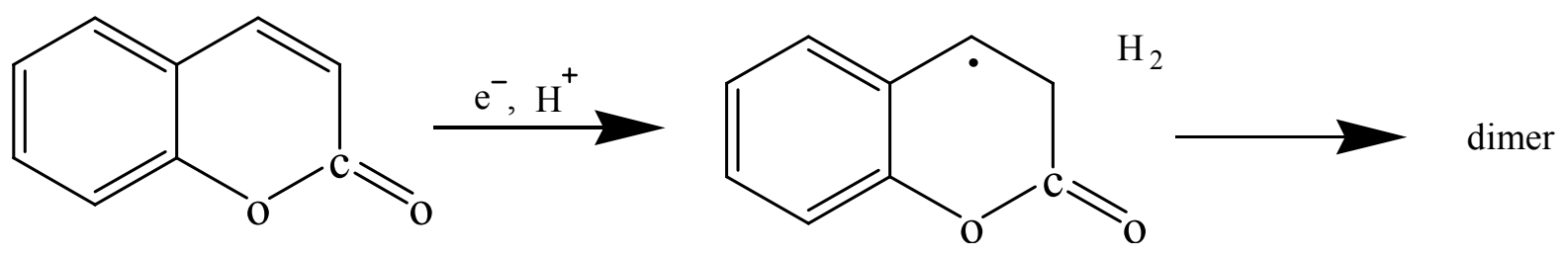

\subsection{Reproducibility and accuracy}

Recovery tests were done on the essential oils and traditional Chinese herbal medicines to evaluate the reproducibility and accuracy of the proposed differential pulse voltammetry (DPV) method. Essential oils and traditional Chinese herbal medicines were spiked with the amounts reported in Table 2 and subjected to the whole procedure. Excellent recoveries (recoveries ranging from $97 \pm 4.0 \%$ to $99 \pm 2.7 \%$ ) and precision were obtained (Table 2). The calibration plots obtained by plotting the peak current against the level of coumarins show good linearity over the range of 2-60 mg/L. For coumarin, the regression equation was:

$$
y=5.464+0.1853 \times(\text { correlation coefficient: } r=0.9990),
$$

and for psoralen:

$$
\mathrm{y}=5.25+0.2351 \times(\mathrm{r}=0.9989)
$$

The relative standard deviation values were between $2.4 \%$ and $4.5 \%$. 
Table 2. Recoveries of coumarins in essential oil and traditional Chinese herbal medicines using differential pulse voltammetry (DPV).

\begin{tabular}{ccccccc}
\hline \multirow{2}{*}{ Samples } & \multicolumn{3}{c}{ Coumarin } & \multicolumn{3}{c}{ Psoralen } \\
& $\begin{array}{c}\text { Added } \\
\text { (mg/L) }\end{array}$ & $\begin{array}{c}\text { Found } \\
\text { (mg/L) }\end{array}$ & $\begin{array}{c}\text { Recovery } \\
\mathbf{( \% )}\end{array}$ & $\begin{array}{c}\text { Added } \\
\text { (mg/L) }\end{array}$ & $\begin{array}{c}\text { Found } \\
\text { (mg/L) }\end{array}$ & $\begin{array}{c}\text { Recovery } \\
(\mathbf{\%})\end{array}$ \\
\hline Lemon essential oil & 16.0 & 14.8 & $99 \pm 2.7$ & --- & --- & --- \\
Psoralea corylifolia & --- & -- & --- & 8.00 & 7.92 & $99 \pm 3.5$ \\
Cnidium monnieri & --- & --- & --- & 8.00 & 7.76 & $97 \pm 4.0$ \\
\hline
\end{tabular}

\subsection{Application to essential oils and traditional chinese herbal medicines}

The proposed DPV method was used to determine the levels of coumarins in essential oils and traditional Chinese herbal medicines. For Angelicae dahuricae, a traditional Chinese herbal medicine, using standard solutions of 8-methoxypsoralen (8-MOP), the peak height of the wave was at $-1.490 \mathrm{~V}$ (Figure 6). Hence, in this study, determining coumarin levels in commercial essential oils and traditional Chinese herbal medicines used a standard addition procedure. The analytical results (Table 3) agreed with those obtained using high-performance liquid chromatography (HPLC).

Figure 6. DPV for 8-MOP from Angelicae dahuricae at an $\mathrm{Hg} / \mathrm{GCE}$ using a standard addition procedure. The peak current values were (i) solid line: $5.114 \mu \mathrm{A}$ at $-1.490 \mathrm{~V}$ with $0 \mathrm{mg} \mathrm{L}^{-1}$ of 8-MOP; (ii) dashed line: $5.659 \mu \mathrm{A}$ at $-1.488 \mathrm{~V}$ with $4.0 \mathrm{mg} \mathrm{L}^{-1}$ of 8-MOP; (iii) dotted line: $6.256 \mu \mathrm{A}$ at $-1.482 \mathrm{~V}$ with $8.0 \mathrm{mg} \mathrm{L}^{-1}$ of 8-MOP; and (iv) dashed/dotted line: $7.461 \mu \mathrm{A}$ at $-1.482 \mathrm{~V}$ with $16 \mathrm{mg} \mathrm{L}^{-1}$ of 8-MOP. Scan rate: $10 \mathrm{mV} / \mathrm{s}$; pulse height: $50 \mathrm{mV}$.

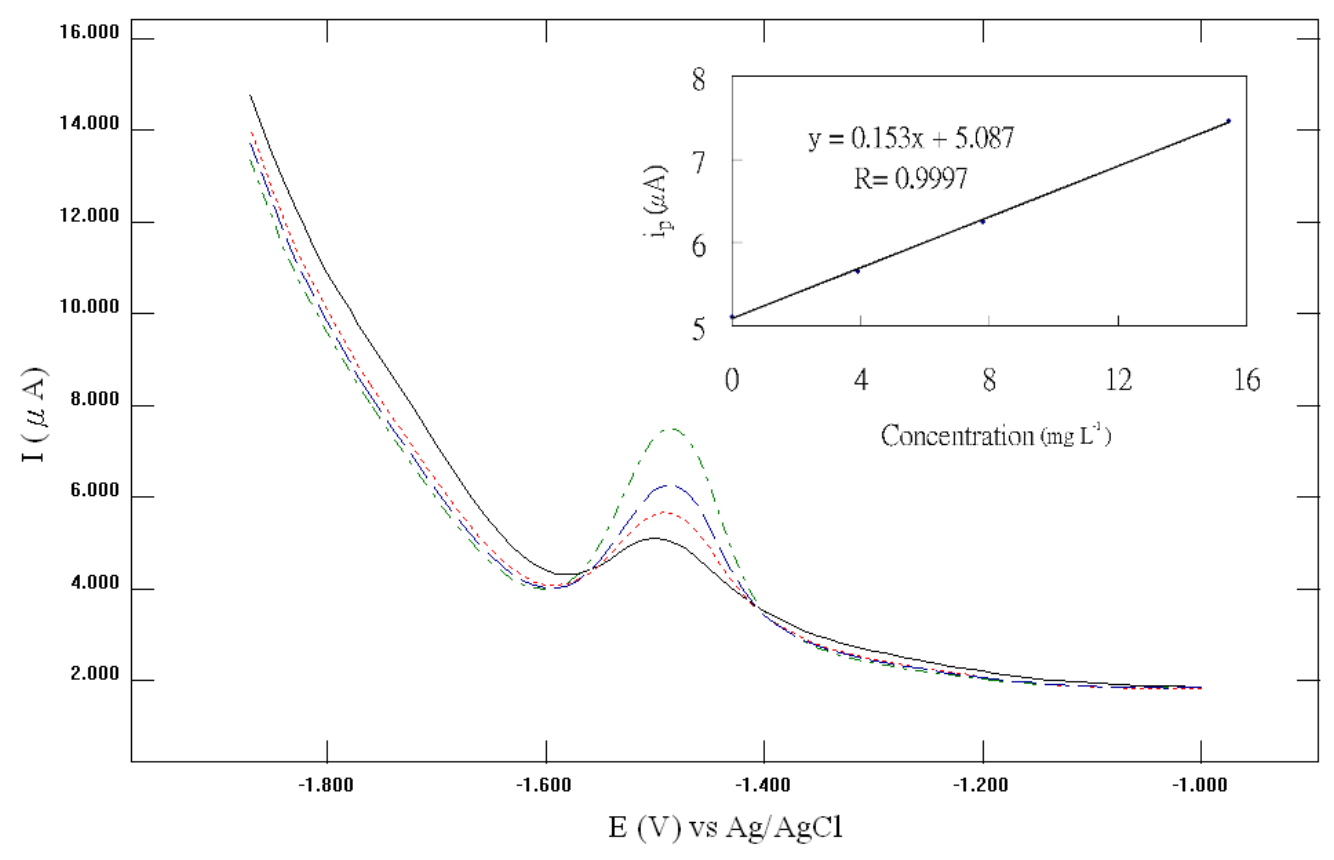


Table 3. Analytical results of determining coumarin levels in commercial pharmaceutical preparations using differential pulse voltammetry (DPV) and liquid chromatography with ultraviolet detection (LC-UV). ${ }^{\text {a }}$

\begin{tabular}{|c|c|c|c|c|c|c|c|c|}
\hline \multirow[b]{3}{*}{ Samples } & \multicolumn{8}{|c|}{ Concentration $(\%, w / w), N=5^{b}$} \\
\hline & \multicolumn{2}{|c|}{ Coumarin } & \multicolumn{2}{|c|}{ Psoralen } & \multicolumn{2}{|c|}{ 5-MOP } & \multicolumn{2}{|c|}{ 8-MOP } \\
\hline & DPV & LC-UV & DPV & LC-UV & DPV & LC-UV & DPV & LC-UV \\
\hline Bergamot essential oil & $--^{c}$ & $--{ }^{c}$ & --- & --- & $\begin{array}{c}0.203 \\
(5.1 \%)\end{array}$ & $\begin{array}{c}0.206 \\
(4.6 \%)\end{array}$ & --- & --- \\
\hline Lime essential oil & $\begin{array}{c}0.034 \\
(1.9 \%)\end{array}$ & $\begin{array}{c}0.031 \\
(1.6 \%)\end{array}$ & --- & --- & --- & --- & --- & --- \\
\hline Lemon essential oil & $\begin{array}{c}0.202 \\
(5.2 \%)\end{array}$ & $\begin{array}{c}0.191 \\
(2.4 \%)\end{array}$ & --- & --- & $\begin{array}{c}0.022 \\
(4.5 \%)\end{array}$ & $\begin{array}{c}0.020 \\
(3.9 \%)\end{array}$ & --- & --- \\
\hline Psoralea corylifolia & --- & --- & $\begin{array}{c}0.148 \\
(4.3 \%)\end{array}$ & $\begin{array}{c}0.143 \\
(3.3 \%)\end{array}$ & --- & --- & --- & --- \\
\hline Angelicae dahuricae & --- & --- & --- & --- & $\begin{array}{c}0.010 \\
(2.3 \%)\end{array}$ & $\begin{array}{c}0.009 \\
(1.1 \%)\end{array}$ & $\begin{array}{c}0.005 \\
(0.31 \%)\end{array}$ & $\begin{array}{c}0.0045 \\
(3.3 \%)\end{array}$ \\
\hline Cnidium monnieri & --- & --- & $\begin{array}{r}0.004 \\
(1.4 \%) \\
\end{array}$ & $\begin{array}{c}0.003 \\
(2.5 \%) \\
\end{array}$ & $\begin{array}{c}0.019 \\
(5.1 \%) \\
\end{array}$ & $\begin{array}{r}0.020 \\
(0.3 \%) \\
\end{array}$ & $\begin{array}{c}0.0022 \\
(4.5 \%) \\
\end{array}$ & $\begin{array}{r}0.0020 \\
(4.3 \%) \\
\end{array}$ \\
\hline
\end{tabular}

${ }^{\mathrm{a}}$ Number of determinations. ${ }^{\mathrm{b}}$ Values in parentheses are the relative standard deviation. ${ }^{\mathrm{c}}$ Not determined.

\section{Experimental}

\subsection{Apparatus}

All electrochemical experiments were done using an EG\&G Princeton Applied Research Model 394 Polarographic Analyzer (Princeton, NJ, USA). We used a three-electrode system consisting of a working electrode $\left(\mathrm{Hg}\left(\mathrm{NO}_{3}\right)_{2} / \mathrm{GCE}, \mathrm{Pb}\left(\mathrm{CH}_{3} \mathrm{COO}\right)_{2} / \mathrm{GCE}\right.$, and $\left.\mathrm{GCE}\right)$, a platinum counter, and an $\mathrm{Ag} / \mathrm{AgCl}$ reference electrode. HPLC was done with a Hitachi model L-7100 pump and model 7125 injector equipped with $20-\mu \mathrm{L}$ sample loop and a model L-7455 photodiode array detector. Chromatograms were acquired and peak areas calculated using a D-7000 chromatogram data integrator.

\subsection{Reagents and materials}

Coumarin and 5-methoxypsoralen (bergapten, 5-MOP) were purchased from Sigma-Aldrich Chem. Co. (St Louis, MO, USA). Psoralen and 8-methoxypsoralen (xanthotoxin, 8-MOP) were purchased from the National Institute for the Control of Pharmaceutical and Biological Products (Beijing, China) and Tokyo Chemical Industry Co., Ltd (Japan), respectively. All other chemicals were analytical reagent grade. Samples of essential oils and medicinal products were bought from a number of retail outlets in southern Taiwan. The BR buffer solutions ( $\mathrm{pH} 1.87-12.05)$ were prepared by mixing $0.5 \mathrm{M}$ phosphoric acid, $0.5 \mathrm{M}$ boric acid, $0.5 \mathrm{M}$ acetic acid, and $0.2 \mathrm{~N}$ sodium hydroxide solutions; $\mathrm{pH}$ was checked using a $\mathrm{pH}$ meter. 


\subsection{Procedures}

\subsubsection{Voltammetric measurements}

The modified $\mathrm{Hg} / \mathrm{GCE}$ and $\mathrm{Pb} / \mathrm{GCE}$ were produced using the following method. A GCE was electrolytically plated with mercury or lead ions from $10 \mathrm{ml}$ of acetate buffer ( $\mathrm{pH} \mathrm{4.13)}$ that was $5.0 \times 10^{-4}$ to $2.0 \times 10^{-3} \mathrm{M}$ mercury (II) or lead (II). Plating time was 2-8 min; potential was scanned from -1.0 to $0.0 \mathrm{~V}$. Sample DC polarography, cyclic and linear sweep, and differential pulse voltammograms were taken of coumarins in BR buffer solutions at $\mathrm{Pb}$ - and $\mathrm{Hg}$-modified GCEs.

\subsubsection{Sample preparation}

Taking into account the content of coumarins or psoralens in the sample, about $0.5-1.0 \mathrm{~g}$ of the latter was accurately weighed, mixed with methanol and deionized water $(1: 1, \mathrm{v} / \mathrm{v})$, and then stirred and refluxed at $70{ }^{\circ} \mathrm{C}$ in a water bath for $1 \mathrm{~h}$. The extract was separated from samples using centrifugation at $6,000 \mathrm{rpm}$ for $30 \mathrm{~min}$. The supernatant volume was extracted with hexane-ethyl acetate $(3: 1, v / v)$ and evaporated to dryness with a stream of nitrogen. The above procedure was repeated three times. The supernatant was transferred into a $10-\mathrm{mL}$ calibrated flask and made up with methanol.

\subsubsection{Determining coumarin levels using DPV}

To obtain calibration plots for the coumarins, $10 \mathrm{~mL}$ of supporting electrolytes were pipetted into a voltammetric cell and deaerated with nitrogen for $4 \mathrm{~min}$ before voltammetric measurement. Using a micropipette, aliquots of coumarin solutions $\left(1,000 \mathrm{mg} / \mathrm{L}^{-1}\right)$ were added and left to deaerate for $2 \mathrm{~min}$. Voltammograms were then taken. Quantitative analyses were done in the differential pulse mode. The potential was set from -0.4 to $-2.0 \mathrm{~V} v \mathrm{~s}$. $\mathrm{Ag} / \mathrm{AgCl}$. The pulse height was $50 \mathrm{mV}$ and the scan rate was $10 \mathrm{mVs}^{-1}$ with a drop time of $1.0 \mathrm{~s}$. For sample solution analysis, $0.1 \mathrm{~mL}$ of the solution was pipetted into a $10-\mathrm{mL}$ calibrated flask and diluted to volume with BR buffer. The solution was analyzed using DPV under the same conditions as for the calibration plot.

\subsubsection{Determining coumarin levels using liquid chromatography}

A stock standard solution was prepared by dissolving $10 \mathrm{mg}$ of coumarins and psoralens in $10 \mathrm{~mL}$ of methanol, respectively. Working standard solutions were prepared from a stock standard solution, in the range $10-80 \mathrm{mg} / \mathrm{L}^{-1}$, in methanol. Reversed phase (RP)-HPLC was done on a Phenomenex Luna $\mathrm{C}_{18}(5 \mathrm{u}, 250 \times 4.6 \mathrm{~mm})$ column with eluted methanol-water $(45: 55, \mathrm{v} / \mathrm{v})$ as the mobile phase at $1 \mathrm{~mL} / \mathrm{min}^{-1}$. Detecting coumarin levels after separation on the $\mathrm{C}_{18}$ column was done using a photodiode array detector. Using an injection value, $20 \mu \mathrm{L}$ of the prepared sample solution and standard solution was chromatographed under the operating conditions described above. Quantitation was based on the peak area of the sample. 


\section{Conclusions}

The electroreduction of coumarins was more sensitive on thin-film mercury electrodes than on glassy carbon electrodes. A thin layer of metal deposited on the cathode surface is sufficient to make the cathode effective, and the thickness of the deposit can be easily adjusted. Electrodeposited metals also offer other advantages compared with cast electrodes. The DPV method described in this paper is simple and can be used for directly monitoring the coumarin levels in essential oils and traditional Chinese herbal medicines.

\section{Acknowledgements}

This work was financially supported by grant NSC 96-2113-M-041-003-MY3 from the National Science Council, Taiwan.

\section{References}

1. Tosun, F.; Kizilay, C.A.; Erol, K.; Kilic, F.S.; Kurkcuoglu, M.; Baser, K.H.C. Anticonvulsant activity of furanocoumarins and essential oils obtained from the fruits of Heracleum crenatifolium. Food Chem. 2008, 107, 990-993.

2. Chen, G.; Zhu, Y.; Wang, Y.; Xu, X.; Lu, T. Determination of bioactive constituents in traditional Chinese medicines by CE with electrochemical detection. Curr. Med. Chem. 2006, 13, 2467-2485.

3. Curini, M.; Cravotto, G.; Epifano, F.; Giannone, G. Chemistry and biological activity of natural and synthetic prenyloxycoumarins. Curr. Med. Chem. 2006, 13, 199-222.

4. Zhou, Z.W.; Liu, P.X. Progress in study of chemical constituents and anti-tumor activities of Cnidium monnieri. Zhongguo Zhong Yao Za Zhi 2005, 30, 1309-1313.

5. Mammen, J.S.; Kleiner, H.E.; DiGiovanni, J.; Sutter, T.R.; Strickland, P.T. Coumarins are competitive inhibitors of cytochrome P450 1B1, with equal potency for allelic variants. Pharmacogenet. Genomics 2005, 15, 183-188.

6. Okamoto, T.; Kobayashi, T.; Yoshida, S. Chemical aspects of coumarin compounds for the prevention of hepatocellular carcinomas. Curr. Med. Chem. 2005, 5, 47-51.

7. Santana, L.; Uriarte, E.; Roleira, F.; Milhazes, N.; Borges, F. Furocoumarins in medicinal chemistry. Synthesis, natural occurrence and biological activity. Curr. Med. Chem. 2004, 11, 3239-3261.

8. Yang, Z., Kinoshita, T., Tanida, A., Sayama, H., Morita, A., Watanabe, N. Analysis of coumarin and its glycosidically bound precursor in Japanese green tea having sweet-herbaceous odour. Food Chem. 2009, 114, 289-294.

9. Zhang, X.; Zhang, J.J.; Xia, Y.Y. Molecular design of coumarin dyes with high efficiency in dye-sensitized solar cells. J. Photochem. Photobio. A Chem. 2008, 194, 167-172.

10. Mi, H.; Qu, L.L.; Ren, Y.L. Study on extraction of coumarins in Cnidium monieri by supercritical $\mathrm{CO}_{2}$ and separation of compositions analysis. Zhongguo Zhong Yao Za Zhi 2005, 30, 1080-1082.

11. Basso, E.; Chilin, A.; Guiotto, A.; Traldi, P. Electrospray mass spectrometry in the differentiation of some isomeric trimethylfurocoumarins. Rapid Commun. Mass Spectrom. 2003, 17, 2781-2787. 
12. Voropaeva, N.E.; Brueva, L.A.; Sokolova, I.V. Spectral features of formation of H-bonded complexes in coumarins and psoralens. Russian Physics J. 1999, 42, 315-318.

13. Mantulin, W.W.; Song, P.S. Excited states of skin-sensitizing coumarins and psoralens. Spectroscopic studies. J. Am. Chem. Soc. 1973, 95, 5122-5129.

14. de Jager, L.S.; Perfetti, G.A.; Diachenko, G.W. Determination of coumarin, vanillin and ethyl vanillin in vanilla extract products: liquid chromatography mass spectrometry method development and validation studies. J. Chromatogr. A 2007, 1145, 83-88.

15. Sproll, C.; Ruge, W.; Andlauer, C.; Godelmann, R.; Lachenmeier, D. W. HPLC analysis and safety assessment of coumarin in foods. Food Chem. 2008, 109, 462-469.

16. Jiang, Y.Q. Analysis of coumarins in Fructus Cnidii by HPLC-ESI-MS. Zhong Yao Cai 2006, 29, 1033-1035.

17. Feger, W.; Brandauer, H.; Gabris, P.; Ziegler, H. Nonvolatiles of commercial lime and grapefruit oils separated by high-speed countercurrent chromatography. J. Agri. Food Chem. 2006, 54, 2242-2252.

18. Teng, W.Y.; Chen, C.C.; Chung, R.S. HPLC comparison of supercritical fluid extraction and solvent extraction of coumarins from the peel of citrus maxima fruit. Phytochem. Anal. 2005, 16, 459-462.

19. Dugo, G.; Quinto Tranchida, P.; Cotroneo, A.; Dugo, P.; Bonaccorsi, I.; Marriott, P.; Shellie, R.; Mondello, L. Advanced and innovative chromatographic techniques for the study of citrus essential oils. Flavour Frag. J. 2005, 20, 249-264.

20. Wang, M.; Jia, M.; Ma, Y.; Jiang, G; Tang, S.; Xia, L. Determination of coumarins content in Radix Angelicae dahuricae by HPLC and UV. Zhong Yao Cai 2004, 27, 826-828.

21. Chen, Z.; Lin, L. Study on coumarin compounds from Exocarpium Citri Grandis. Zhong Yao Cai 2004, 27, 577-578.

22. Tao, Z.Y.; Chen, W.S.; Zhang, W.D.; Sun, L.N.; Zheng, S.Q.; You, L.; Qiao, C.Z. Studies on the coumarins in the root of Zanthoxylum dimorphophyllum. Zhongguo Zhong Yao Za Zhi 2003, 28, 345-346.

23. Cavazza, A.; Bartle, K.D.; Dugo, P.; Mondello, L. Analysis of oxygen heterocyclic compounds in citrus essential oils by capillary electrochromatography and comparison with HPLC. Chromatographia 2001, 53, 57-62.

24. Bonaccorsi, I.; Dugo, G.; Mcnair, H.M.; Dugo, P. Rapid HPLC methods for the analysis of the oxygen heterocyclic fraction in citrus essential oils. Ital. J. Food Sci. 2000, 12, 485-491.

25. Liu, H.M.; Zhang, M.X. Extraction of coumarins from Angelica dahurica by supercritical extraction and GC-MS analysis. Zhongguo Zhong Yao Za Zhi 2004, 29, 241-244.

26. Della Porta, G.; Reverchon, E.; Chouchi, D.; Barth, D. Mandarin and lime peel oil processing by supercritical $\mathrm{CO}_{2}$ desorption: deterpenation and high molecular weight compound elimination. $J$. Essent. Oil Res. 1997, 9, 515-522.

27. Starrantino, A.; Terranova, G.; Dugo, P.; Bonaccorsi, I.; Mondello, L. On the genuineness of citrus essential oils. Part IL. Chemical characterization of the essential oil of new hybrids of lemon obtained in Sicily. Flavour Frag. J. 1997, 12, 153-161. 
28. Wang, L.H.; Jiang, S.Y. Simultaneous determination of urinary metabolites of methoxypsoralens in human and Umbelliferae medicines by high-performance liquid chromatography. $J$. Chromatogr. Sci. 2006, 44, 473-477.

29. Wang, L.H.; Lien, C.L. Determination of urinary metabolites of coumarin in human urine by HPLC. J. Liq. Chromatigr. Rel. Tech. 2004, 27, 3077-3088.

30. Constantinescu, E.; Dima, G.; Hillebrand, M.; Andrei, M. Cyclic voltammetry of some 3,3'-methylene-bis(4-hydroxycoumarin) derivatives. Rev. Roum. Chim. 2002, 47, 763-768.

31. Kumar, A.; Sharma, R. Electrochemical investigations of 3-(4'-methyl)phenylazo-8-aldehydo4-methyl coumarin. Bull. Electrochem. 2002, 18, 71-74.

32. Cheng, C.C.; West, A.C. Nickel deposition in the presence of coumarin: an electrochemical impedance spectroscopy study. J. Electrochem. Soc. 1997, 144, 3050-3056.

33. Chen, T.; Platz, M.S.; Robert, M.; Savéant, J.M.; Marcinek, A.; Rogowski, J.; Gebicki, J.; Zhu, Z.; Bally, T. Electron transfer chemistry of psoralen and coumarin derivatives by means of radiolytic and electrochemical experiments. J. Physic. Chem. A 1997, 101, 2124-2130.

34. Wang, L.H.; Jiang, S.Y.; Lan, Y.Z. Voltammetric behavior coumarins and psoralens at a carbon fiber ultramicroelectrodes and their determination in citrus essential oils. Bull. Electrochem. 2004, 20, 445-451.

35. Harle, A.J.; Lyons, L.E. The polarographic reduction of some heterocyclic molecules, part II. Coumarin and certain derivatives thereof. J. Chem. Soc. 1950, 325, 1575-1578.

36. Longmuir, I.S. Advances in Polarography; Pergamon Press Ltd.: London, UK, 1960; Vol. 3, p. 805.

37. Zuman, P.; Perrin, C.L. Organic Polarography; Interscience Publishers: New York, NY, USA, 1969; p. 229.

Sample Availability: Samples of the compounds are available from the authors.

(C) 2009 by the authors; licensee Molecular Diversity Preservation International, Basel, Switzerland. This article is an open-access article distributed under the terms and conditions of the Creative Commons Attribution license (http://creativecommons.org/licenses/by/3.0/). 